\title{
A Review on the Strengthening of Nanostructured Materials
}

\author{
Liang Tian ${ }^{\# *}$ and Lin $\mathrm{Li}^{\wedge}$ \\ \#Department of Materials Science and Engineering, University of Michigan, Ann Arbor, Ann Arbor, MI, 48109 \\ ${ }^{\wedge}$ Department of Metallurgical and Materials Engineering, University of Alabama, Tuscaloosa, AL 35487 \\ Received 05 Jan 2018, Accepted 07 March 2018, Available online 09 March 2018, Vol.8, No.2 (March/April 2018)
}

\begin{abstract}
Nanostructured materials, whose characteristic microstructure size is under $100 \mathrm{~nm}$, can be either single-phase nanocrystalline materials or multi-phase nanocomposite materials. Nanocrystalline materials can also be treated as nanocomposites with grain interior as matrix and grain boundary as secondary phase. The strengthening models of nanostructured materials resemble those strengthening models of conventional composite structures, but have substantial deviations from conventional strengthening mechanisms due to their distinctive nanoscale structure and the complex hierarchy of their nanoscale microstructure. This paper reviewed the current progress in developments of strengthening models for nanostructured materials with emphasis on single-phase nanocrystalline and multiphase nanocomposite materials, which would help guide the design of new nanostructured materials and other similar nanoscale composite structures. Furthermore, practical large scale industrial applications of high strength nanostructured materials require these materials to possess decent formability, ductility or other functional properties to satisfy both structural and multifunctional applications. Therefore, the latest developments of novel nanostructured materials are discussed to highlight their potential of overcoming the strength ductility trade-off and strength-conductivity trade-off by various approaches. Their complex and distinctive nanoscale microstructure suggests the potential challenges and opportunities in developing new strengthening models for designing future advanced nanostructured materials with unprecedented properties.
\end{abstract}

Keywords: Nanostructured materials; strength; model; nanocomposite; interface; strength-ductility/conductivity trade-offs; size effect; nanoprecipitates and nanotubes; covetic materials; additive manufacturing

\section{Introduction}

Nanostructured materials are materials whose characteristic microstructural length scale is less than $100 \mathrm{~nm}$ and usually on the order of a few nanometers (Gleiter,2000). Nanocrystalline materials, as single phase nanostructured materials, was introduced by Gleiter to be defined as polycrystals with a grain size under $100 \mathrm{~nm}$ (Gleiter,1989). The properties of nanocrystalline materials are superior to those of single crystals, coarse-grained polycrystals and amorphous glasses with the same average chemical composition, such as increase strength, hardness, ductility, toughness, and reduced elastic modulus (Meyers et al,2006;Suryanarayana,1994). These superior properties should be attributed to the reduced size of the crystallites as well as the large amount of grain boundaries. For example, when the grain size reaches 5 nanometers, these materials consist of about 50 vol.\% crystalline component phase and 50 vol.\% grain boundary phase. Grain boundary

*Corresponding author's ORCID ID: 0000-0003-4876-968X;

Tel: +1 515-509-0857; Email: liangtianisu@gmail.com/lilangt@umich.edu, DOI: https://doi.org/10.14741/ijcet/v.8.2.7 belongs to a type of interfaces called homophase interfaces, which separate crystals of the same structure and chemistry but different orientation. The properties of interfaces are primarily determined by their interactions with the defects such as zerodimensional point defects interstitials and vacancies, one-dimensional dislocations, two-dimensional twin boundaries (Beyerlein et al,2015). Therefore, the properties of nanocrystalline materials are largely determined by the dominant role of grain boundary in interacting with defects as grain size reduced (Raabe $e t$ al,2014;Ma et al,2006;Chen et al,2003;Dao et al,2007). Similarly, nanocomposites are multi-phase nanostructured materials with the characteristic size of second phase being nanoscale. Their properties are primarily determined by the heterophase interfaces that can interact defects in the similar way as homophase interface, e.g. acting as barrier to dislocations transmission.

Understanding the size effect in nanostructured materials, i.e., the relation between characteristic microstructural size and various properties of nanostructured materials would help design advanced materials that exhibit technologically important 
properties (Tian et al,2013;Tian et al,2017;Suryanarayana et al,2011). Among all interesting properties of nanostructured materials, strength is the most important property (Rostislav et $a l, 2009)$. Therefore, in this paper, we reviewed the current developments of the strengthening theories of nanostructured materials by separating into two parts: strengthening models for nanocrystalline materials and strengthening models for nanocomposite materials. In addition, latest developments of novel nanostructured materials with unprecedented microstructure complexity and hierarchy are highlighted for future research in developing novel strengthening models to expand the current microstructure strength design space. It is the aim of the authors to provide insights into future research in the strength of nanostructured materials.

\section{Strengthening models of nanocrystalline materials}

Compared with their microscale counterpart, the unusually high strength of nanocrystalline materials is of significant interests to numerous researchers (Bringa et al,2005;Schiøtz et al,2003;Mercier et al,2007). It is well known that a Hall-Petch model exists for conventional polycrystalline materials, which gives an inverse relation between strength and square root of grain size. In this model, the grain boundaries act as barriers to lattice dislocations motion, which is the carrier of plastic deformation. This model usually works when the grain size is above 1 microns. When the grain size is between 1 micron and $100 \mathrm{~nm}$, the Hall-Petch relation roughly holds, but deviates from the classical -0.5 exponent to a value close to zero. However, this Hall-Petch model breaks down and the role of grain boundary change when the grain size further reduces to the nanoscale regime (Meyers et al,2006). When the grain size decreases below a critical size (e.g. around tens nanometers), the grain boundaries become the dominating phase, and the grain boundary mediated deformation mechanism is responsible for the plastic deformation and the dependence of strength on grain size obeys an abnormal Hall-Petch relationship, i.e., the strength decrease with reducing grain size. This decreased flow stress with decreasing grain size is generally known as inverse Hall-Petch relation (Suryanarayana et al,2011;Carlton et al,2007;Hahn et al,1997). This transition from a dislocation based to a grain boundary based deformation mechanism leads to a maximum strength at a critical grain size that strongly depends on the stacking fault energy of fcc metals, the elastic properties of the metal, and the applied stress (Schiøtz et al,2003; Mercier et al,2007; Yamakov et al,2003).

The deformation behavior of nanocrystalline materials can be regarded as the deformation of a two phase composite with grain interiors and grain boundaries as component phases (Mercier et al,2007).
When decreasing grain size, the deformation mechanism of nanocrystalline materials transitioned from one to another based on different physical mechanisms of each component phase (e.g. lattice dislocation motion, grain boundary sliding, diffusion plasticity mechanisms, twinning mechanism) of plastic flow (Schiøtz et al,2003;Mercier et al,2007). Yamakov et al (Yamakov et al,2003) proposed a two-dimensional deformation-mechanism map for the deformation behavior of nanocrystalline fcc metals at low temperature. They also emphasized that the crossover in the deformation mechanism arises from the lengthscale competition between the grain size and the dislocation splitting distance. Chen et al (Chen et $a l, 2003$ ) observed the deformation twinning in plastically deformed nanocrystalline aluminum and explained the transition of deformation mechanisms from normal dislocation slip to partial dislocation activity when grain size decreases to tens of nanometers, which interpret the unusual mechanical behavior of nanocrystalline materials.

The specific mechanism for deviations of grain size dependency of nanocrystalline materials from the conventional Hall-Petch grain size relation is the subject of controversy, though the unusual strength and deformation behavior of nanocrystalline materials are definitely caused by their nanoscale structure and the extremely high volume fraction of the grain boundary phase. For example, Carlton et al (Carlton et $a l, 2007)$ attributed this inverse Hall-Petch relation to the statistical absorption of dislocations by grain boundaries. Other explanations of the inverse HallPetch effect are (Hahn et al,1997): modifications of the dislocation pile-up at grain boundary; the dislocations emission from grain boundary; significant increase in grain boundary triple junctions and quadruple nodes; grain-boundary sliding and other diffusion based mechanism at much lower temperatures. Suryanarayana et al (Suryanarayana et al,2011) also proposed that when grain size is below the critical grain size, the observed softening at smaller grain sizes could be attributed to the increased triple junction volume fraction considerably over the grain boundary volume fraction.

Various theoretical models have been developed to describe the plastic deformation mechanism and the strength in nanocrystalline materials. Two different approaches have been generally adopted to develop these models as demonstrated in Fig. 1. First type of models, using the rule of mixtures approach, take nanocrystalline materials as two-phase or multi-phase composites with grain interiors and grain boundaries as phases and predict their properties from the grain interior and grain boundary phases' averaged mechanical properties and volume fractions (Voyiadjis et al,2010). The downside of this model lies in the difficult of extracting the mechanical properties of grain boundary phase. Second type of models, using physical mechanisms based approach, focus on the evolution of defects and grain boundary structures in terms of different physical mechanisms of plastic 
deformation (e.g. lattice dislocation motion, grain boundary sliding, diffusion plasticity mechanisms) (Gutkin et al,2004). They emphasize nanoscale size effects and the competition between various deformation mechanisms and the effects of a distribution of grain size on this competition in nanocrystalline materials. This approach allows the simultaneous operation of different deformation mechanisms in various local areas of nanocrystalline material with different grain size distributions to get averaged mechanical properties of nanocrystalline materials.

(a)

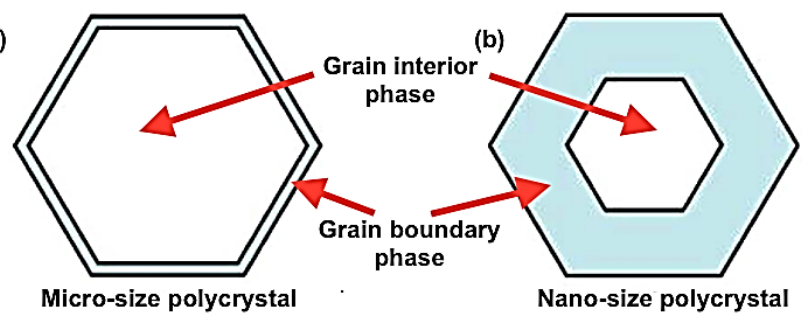

(c)

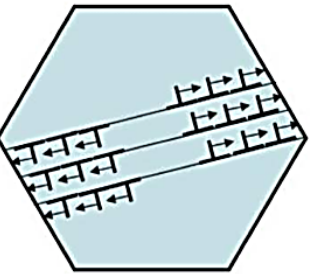

Dislocations pile up at grain boundary

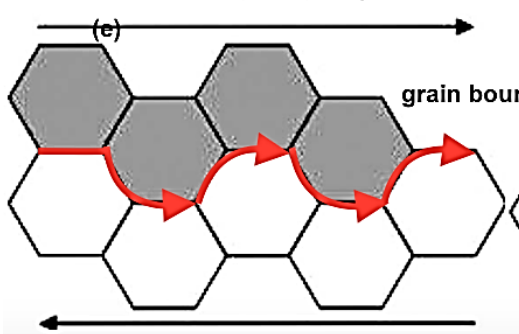

(d)

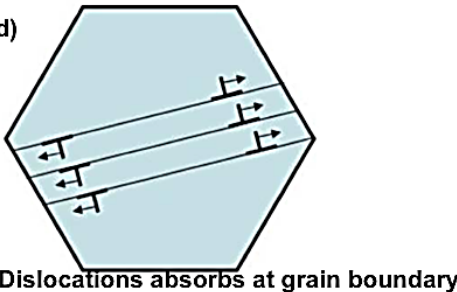

(f)

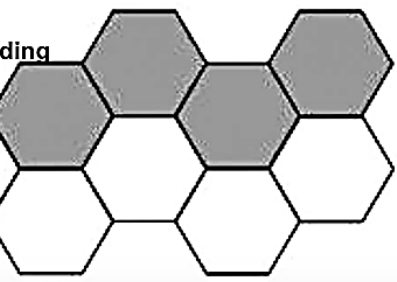

Fig.1 A comparison of developing strengthening models of nanocrystalline materials using the rule of mixtures approach and the physical mechanisms approach: (a) and (b) the rule of mixtures approach comprising of the grain interior phase and the grain boundary phase with the possibility to include grain boundary triple junctions and quadruple nodes as addition phases. The difficulty of this approach lies in an accurate representation of grain

boundary phase properties, which are generally estimated by the properties of amorphous phase with similar composition. (c-f) the physical mechanism based approach to develop strengthening model. (c) and (d) illustrates the interaction of dislocations with grain boundaries: (c) grain boundaries act as barrier to dislocations motion so that dislocations pile up at grain boundary when the grain size is microscale; (d) grain boundaries act as sink for dislocations when the grain size reduced to nanoscale and is below a critical size so that dislocations density decrease to soften the materials to cause the inverse Hall-Petch relation. In this case, the deformation can be accommodated by the grain boundary mediated deformation mechanisms such as the grain boundary sliding depicted in (e) and (f). (Figures adapted from (Meyers et al,2006)).

\section{The rule of mixtures strengthening models}

Strengthening models based on the rule of mixture approach take the volumetric weighted sum of strength for each phase component. Kock et al (Kocks,1970) first brought up the idea to treat grain boundary layers of thickness $t$ as a separate phase beside grain interior bulk phase. He obtained an inverse relation between yield strength of a polycrystalline solid and grain size under the assumption that strength of grain boundary and grain interior are independent of the grain size. Based on this idea, Gryaznov et al (Gryaznov et al,1993) extend Kocks' work to obtain a generalized empirical analogue of Hall-Petch law at large grain size and predict the existence of a critical grain size below which the HallPetch relation breaks down. In their model, the critical grain size and the deviation from the Hall-Petch law is determined by the atomic density of the interfaces. Similar studies (Carsley et al,1995;Gutkin et al,1993) based on the rule of mixtures have been performed to treat the grain boundary phase as amorphous materials of close chemical composition since the atoms in grain boundary of nanocrystalline materials are in a totally disordered state that resembles amorphous material. Kim et al (Kim,1998) had similar idea of taking the properties of the grain boundary phase as those of the amorphous counterpart. He also proposed the existence of a critical grain size below which usual dislocation mechanisms of plasticity and 
strengthening stops working and Hall-Petch relation breaks down to cause no strengthening effect. Their model can over-predict the experimental values due to the possible residual porosity inside nanocrystalline materials. These previous models taking grain boundary phase through the properties of amorphous counterpart appears to be plausible when the grain size of nanocrystalline materials is rather large (above $20 \mathrm{~nm}$ ), while they can overestimate the yield stress or microhardness of nanocrystalline materials with small grain size by shifting maximal values to smaller grain sizes. This should be related to the fact that the properties of grain boundary phase are treated as constants, instead of a variable quantity. Konstantinidis and Aifantis (Konstantinidis et al,1998) proposed a rule of mixture model that assumes the microhardness of the grain boundary phase satisfied the Hall-Petch relation with effective parameters. The deviations from the Hall-Petch relation of microhardness in small grain size region was attributed to the fact that the interaction mechanism between dislocations and the grain boundaries changed from dislocation pinning to Orowan bypassing. The critical grain size is then the grain size at which the interaction mechanism changed and the maximum microhardness achieved. Wang et al (Wang et al,1995) proposed a composite model with the grain interior, grain boundaries, their triple junctions and quadruple nodes as constitute phases. The model can assess the grain size dependence of the yield stress for each constitute phase. They also found that the grain size dependence of creep rate is higher for triple line diffusion than that of lattice and grain boundary diffusion. All these rule of mixtures models did not account for the role of physical mechanisms of plastic deformation.

\section{Physical mechanism based strengthening models}

Strengthening models based on physical mechanism based approach study the effect of grain size on the crossover of various physical deformation mechanisms (Tian,2017). Various deformation mechanisms can simultaneously operate inside nanocrystalline materials to be responsible for their strength. Conventional lattice dislocation motion impeded by grain boundaries would lead to a dislocation pile-up model that cause stress concentration and dislocation sources regeneration in the neighboring grains to initiate dislocation transmission and macroscopic slip, which would lead to the well-known Hall-Petch relation. This relation holds only when there are a large number of dislocations piled up in grain interior. Grabski and Korski (Grabski et al,1970) mentioned that grain boundaries can act predominately as sinks for dislocations, i.e. dislocations were absorbed by the grain boundaries to cause the decrease of dislocation density and flow stress. Li et al (Li et al,2009) developed a quantized crystal plasticity model, in which the grain-size dependent stochastic nature of dislocation nucleation at grain boundaries leads to a nano-scale strengthening. The active role of grain boundaries such as grain boundary sliding or diffusion also contributed to the deformation of nanocrystalline materials when grain size is smaller than tens of nanometers. The effect of grain size on the deformation behavior of nanocrystalline materials will be reflected by the competition between various deformation mechanisms depending on the grain size, or the co-operation of multiple deformation mechanisms due to a grain size distribution. Hahn et al (Hahn et al,1997) proposed a model to attribute the accommodation mechanism for the grain boundary sliding to the local migration of grain boundaries. Hahn et al (Hahn et al,1997) also proposed a grain boundary sliding mechanism controlled yield strength model for nanocrystalline materials by equating the work needed to create the extra grain boundaries and the work done by external force to cause the grain boundary sliding. Gutkin et al (Gutkin et al,2004) attributed the strengthening of nanocrystalline materials to the triple junctions of grain boundaries as obstacles for grain boundary sliding. The dependence of the yield stress on grain size and triple junction angles was found to be depending on a competition between conventional dislocation slip and grain boundary sliding in asfabricated sample and be a competition between conventional dislocation slip and Coble creep in heat treated nanocrystalline materials. They also considered the distributions of grain sizes and triple junction angle that mimic those in real specimens Previous models lack a unified way to represent the relation between strength and grain size in a wide range of grain size. Masumura et al (Masumura et $a l, 1998)$ proposed a model and developed an analytical expression for $\tau$ as a function of the inverse square root of $d$ in a simple and approximate manner that could be compared with experimental data over a wide range of grain sizes. It might also be worthwhile to mention that $\mathrm{Pu}$ et al (Pu et al,2017) studied the effect of grain size, loading condition, materials parameters on the failure modes of polycrystalline materials to propose a failure mechanism map by using their diffusioncoupled cohesive zone model. The defects after failure can be imaged by a damage imaging method developed by He et al (Jiaze et al,2016) to estimate the defect reflectivity correlated with the young's modulus or stiffness in damaged regions.

\section{Combined models}

Models have been developed by combining the rule of mixture approach with the physical mechanism based approach. Kim et al (Kim et al,2000) proposed a rule of mixtures model that takes the plasticity and deformation mechanism into consideration. They used the unified viscoplastic constitutive relations to model the mechanical properties of the crystalline phase by incorporating dislocation density evolution and diffusion creep. The deformation mechanism for the grain-boundary phase is modelled as a diffusional flow 
through the grain boundary. Therefore, the grain size dependence of the overall plastic deformation of polycrystalline materials can be derived with rate effects considered. Voyiadjis et al (Voyiadjis et $a l, 2010)$ proposed a generalized strengthening model that can predict the strength of polycrystals from micro-size to nano-size range. The polycrystal structure was taken as a three-phase composite in terms of the grain interior, the grain boundary and the triple junctions. Each phase is treated differently based on the size of crystal from micro to nano size. Each phase used physics mechanism based strengthening models, considering the effect of grain boundary sliding and grain boundary separation mechanisms. One interesting model combining physics mechanism based models with micromechanics models is a high strain rate strengthening model for nanocrystalline materials developed by Zhu et al (Zhu et al,2008). They used the Voigt model instead of the rule of mixtures model to combine the mechanical properties of grain interior phase with the constitutive relation of grain boundary phase.

In summary, the deformation behavior of plastic flow in nanocrystalline materials can be very complex and difficult to identify the possible deformation mechanisms due to their very complicated structures at various length scales and the transition of deformation mechanism with reducing grain size. In addition, the possible operations of multiple deformation mechanisms due to a distribution of grain sizes could complicate the identification of a single deformation mechanism by experiments (Gutkin et al,2004;Zhu et al,2006). Furthermore, the deformation mechanism can be different in different nanocrystalline materials based on their tendency to form partial dislocations and stacking fault (Yamakov et al,2003). Even in the same nanocrystalline materials, the deformation mechanism is also highly sensitive to operating condition such as the applied stress, temperature and strain rate (Yamakov et al,2003). In addition to the grain size effect, the strengthening and deformation mechanism of nanocrystalline materials can be significantly affected by the solid solution effect, which contradicts with traditional solid solution effect (Rupert et al,2011). Further experimental and theoretical investigations in deformation behavior of nanocrystalline materials are needed for generalized understanding of a combination of multiple deformation mechanisms under various material characteristics, grain size distributions and loading conditions.

\section{Strengthening models of nanocomposite materials}

The unusually high strength of metallic nanocomposite underestimated by the rule of mixtures has been investigated by many researchers to be the effect of interfacial barrier to dislocation motion and transmission. For example, Bevk et al (Bevk et al,1978) studied $\mathrm{Cu}-18$ vol\% $\mathrm{Nb}$ composites with a reported ultimate tensile strength of $2200 \mathrm{MPa}$. This strength value is 4 times higher than the value predicted by rule of mixtures for $\mathrm{Cu}$ and $\mathrm{Nb}$. Trybus and Spitzig (Trybus et al,1989) studied rolled and wire-drawn $\mathrm{Cu}-\mathrm{Nb}$ composite. The strengths in rolled and wire drawn $\mathrm{Cu}-\mathrm{Nb}$ both increase as deformation increases. Rolled $\mathrm{Cu}-\mathrm{Nb}$ showed a weaker strength dependence on filament spacing than that of wiredrawn $\mathrm{Cu}-\mathrm{Nb}$ though both follows the Hall-Petch relationship. Tian et al (Tian et al,2017;Tian et al,2013;Tian,2015) studied the microstructure strength relation in a novel Al-Ca composites and found that the strength value $476 \mathrm{MPa}$ of $\mathrm{Al}-20 \mathrm{vol} \% \mathrm{Ca}$ composite is more than 4 times of that predicted by the rule of mixtures of pure $\mathrm{Al}$ and Ca strength (Shaw et al,2016). The Al-Ca composite processed by power metallurgy (Tian et al,2017) and severe plastic deformation, has a high strength (Tian et al,2017;Tian et al,2014), high electrical conductivity (Tian et $a l, 2017$;Tian et al,2014) that can be used as high voltage power transmission electrical conductor (Tian et al,2013). The high strength of Al-Ca composite has been demonstrated in Fig. 2 .

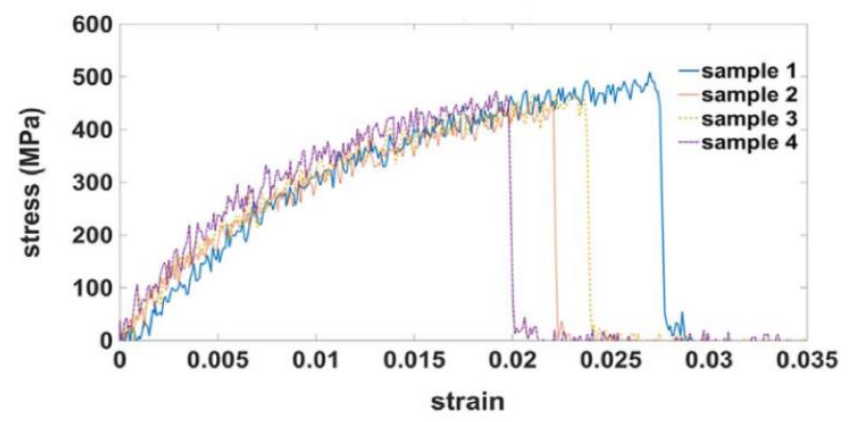

Fig.2 The stress-strain curves of a novel lightweight, high strength, high conductivity Al-Ca composite (Tian et al,2017). The strength of Al-Ca composite is 476 $\mathrm{MPa}$, which is 4 times more than that of the rule of mixtures prediction.

Two general approaches to develop strengthening models for these nanocomposites have been illustrated in Fig.3. The phenomenological models used empirical relations to describe the interface, neglecting the interface structures that are critical for developing fundamental microstructure-strength relationship (Sinnott et al,2003). The strain gradient models linked the interface structure with geometrically necessary dislocations, which is physical mechanism based approach to describe the strengthening of nanocomposite. 


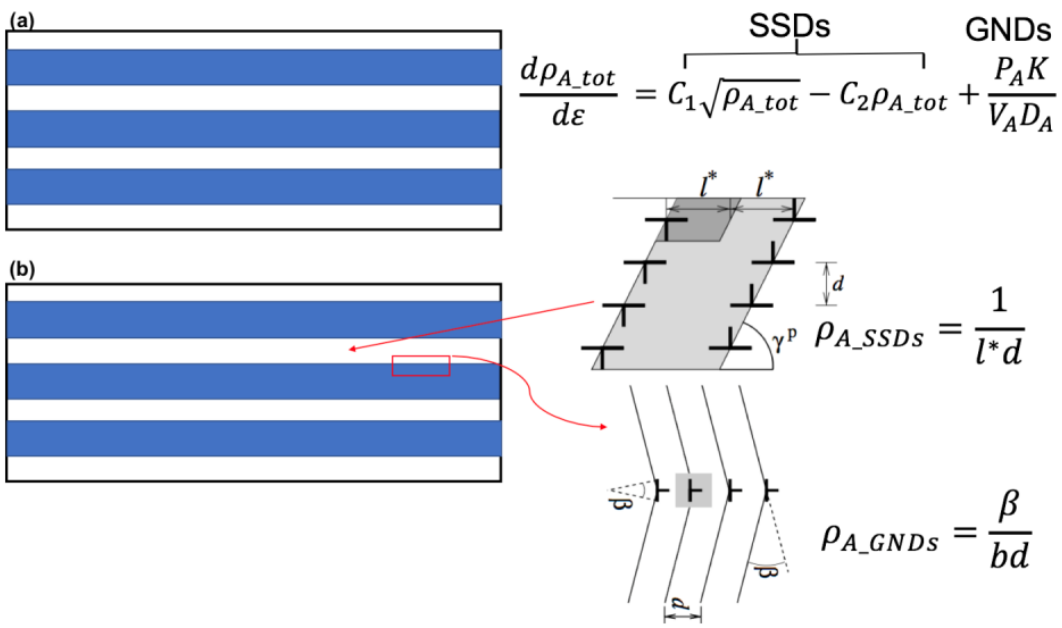

Fig.3 An illustration to compare the strengthening models of nanocomposite developed by the phenomenological approach and strain gradient approach (phase $\mathrm{A}$ being the matrix phase, shaded phase $\mathrm{B}$ being the reinforcement phase): (a) this phenomenological approach example developed by Funkenbusch et al (Funkenbusch et al,1987)

combining the evolution of statistically stored dislocations (SSDs) and geometrically necessary dislocations (GNDs) together into one master equation with many fitting parameters. (b) this strain gradient example linked

the SSDs and GNDs density to their corresponding physical mechanisms (Brinckmann et al,2006). The GNDs density will dominate the strengthening when the characteristic length scale of the reinforcement phase is much smaller than the intrinsic material length scale (Tian et al,2014). (Figures adapted from (Brinckmann et al,2006))

\section{Phenomenological models}

Various strengthening models of metallic nanocomposite have been proposed to explain their anomalously high strength. Early developments of strengthening models focused on empirical fitting in a qualitative way. Bevk et al (Bevk et al,1978) first proposed the hypothesis that a Hall-Petch relation between the anomalous strength of $\mathrm{Cu}-\mathrm{Nb}$ composites and the filament spacing. Despite the low volume fraction of $\mathrm{Nb}$ filaments, the $\mathrm{Cu}-\mathrm{Nb}$ composite can still achieve a strength close to that of copper whiskers. Spitzig et al (Spitzig et al,1987) further suggested a Hall-Petch barrier model, which attributed the strengthening effect to the role of the interface as a barrier to dislocation motion that yields the Hall-Petch dependence of the strength of a composite on the filamentary spacing. Another model was proposed by Funkenbusch and Courtney (Funkenbusch et al,1987) as a work hardening model. This model attributed the incremental strength above the rule of mixtures prediction to the so-called geometrically necessary dislocations emitted from the interface to accommodate the strain incompatibility across the interphase boundary. These geometrically necessary dislocations have the same strengthening effect as statistically stored dislocations according to Taylor's hardening law. The density of geometrically necessary dislocations is proportional to the strain incompatibility by a geometrical constant serving as a fitting parameter. Both of these two models have their limitations. The Hall-Petch barrier model failed to explain the high strength of cold-worked two phase materials relative to single phase material with similar filament (i.e., grain) spacing. The work-hardening model failed to explain the low dislocation density observed in high strength $\mathrm{Cu}-\mathrm{Nb}$ composite (Trybus et al,1989). However, these two model mechanisms are not completely exclusive. One mechanism will be predominated over the other depending on deformation processing and crystal structure of metal phases. Interface barrier effect appears to be the major strengthening mechanism at large deformation (true strain above ten), at which interfaces served as sinks for dislocations and inhibited the generation and development of new dislocations from Frank-Read dislocation sources due to the fine interphase spacing (Funkenbusch et al,1987). The geometrically necessary dislocations (GNDs) are mainly responsible for the incremental strength when two metal phases with different crystal structures are deformed to a moderate strain so that strain accommodation by GNDs between two phases is necessary. Raabe et al (Raabe et al,1995) brought up a modified linear rule of mixture model to include a Hall-Petch contribution from phase boundaries for simulating the strength of fcc/bcc type composite. However, this model requires mathematical assumptions to explain the origin of the Hall-Petch contribution from the interface without physical mechanism justification, which casts some doubt over the universality of the model. All three types of models can only be counted as semi-quantitative models because they contain many empirical fitting parameters. Therefore, physical mechanism based interface models can be developed to address the anomalously high strength of metal metal composite.

\section{Strain gradient theories}

The physics based strengthening models of nanocomposite can be developed through a class of 
physics based theories called strain gradient theories to explain the size dependent deformation behavior. The dependence of strength on the characteristic size of secondary filament is called size effect, which can be interpreted by taking the interfaces as the source of geometrically necessary dislocations (GNDs) to accommodate strain incompatibility across interface (Brinckmann et al,2006;Huang et al,2004;Fleck et al,1994;Stölken et al,1998;Shell De Guzman et al,2011). For example, Lloyd (Lloyd,1994) observed an obvious increase in the strength of $\mathrm{SiC}$-particle-reinforced composite when the particle diameter decreased from 16 to $7.5 \mu \mathrm{m}$ with a fixed particle volume fraction of 15 $\%$. The conventional plasticity theories failed to interpret this size effect since no intrinsic material length scale was introduced (Abu Al-Rub et al,2006). A material length scale was introduced in strain gradient plasticity theories to compare with the characteristic microstructure dimension to explain the size effect (Gao et al,1999). The concept of strain gradient has also been adopted to explain the grain size dependent yield stress of polycrystalline materials-the HallPetch relation. Strain gradients in small dimension materials are accommodated by the GNDs to distort the crystalline lattice structure to improve the lattice structural continuity across interface (Ashby,1970). Like statistically stored dislocations (SSDs), an increased density of GNDs will also strengthen crystals by Taylor's hardening law so that the strain gradient affects the plasticity behavior of metals by the

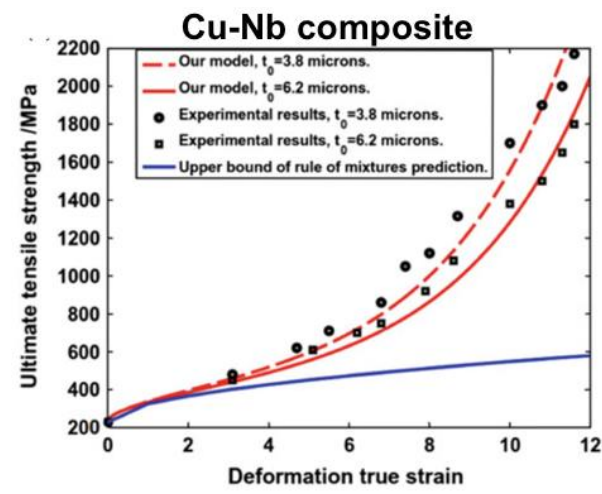

dislocation pile-up. Based on the concept of strain gradient plasticity, Tian et al (Tian et al,2014) developed a dislocation density based strain gradient model for predicting the high strength in deformation processed metal metal composites as shown in Fig.4. The idea to incorporate the strain gradient effect into modeling the yield stress of metal metal composites originated from the fact that the filamentary microstructure in metal metal composite is in the submicron size (as low as $20 \mathrm{~nm}$ ) that is obviously comparable with a common intrinsic material length scale from a fraction of a micron to tens of microns. The fiber matrix interfaces can be a realistic source to generate the GNDs to accommodate a strain gradient. They used a simple non-continuum formulation based on the assumption that effective strain gradient is directly proportional to the deformation true strain during severe plastic deformation of the composite and inversely proportional to the characteristic microstructure length for uniaxial deformation mode. The average effect of different orientations of the slip systems is implemented as a material characteristic parameter. For each metal phase, its yield stress is a modified yield stress considering the work hardening effect from both statistically stored dislocations and GNDs whose density can be determined by strain hardening curve and effective strain gradient, respectively. The yield strength of the composite would be the volumetric weighted average of modified yield strength of two metal phases.

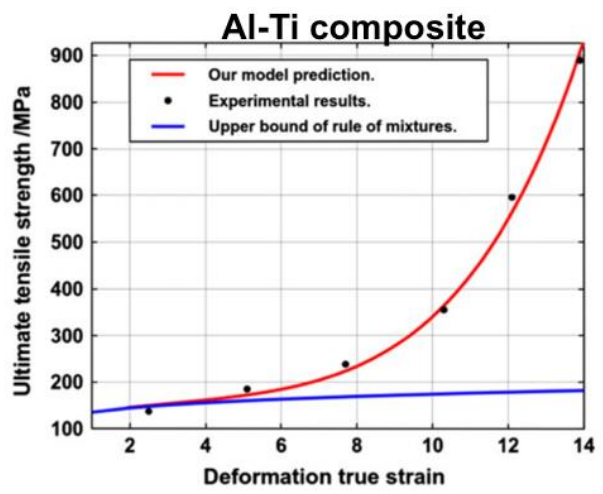

Fig.4 The dislocation density based strain gradient strengthening model developed by Tian et al (Tian et al,2014) predicts the strength of metal-metal composites with a comparison with experimental data. The left figure is $\mathrm{Cu}-$ $\mathrm{Nb}$ composite. The right figure is the Al-Ti composite.

\section{Interface-defects interactions theory}

The strengthening models can also be developed based on the relation between strength and defects, whose density evolution is controlled by interacting with interfaces. In addition to the role of acting as the barrier and source of defects, the other interactions of interfaces with defects can be: sinks for defects due to absorption and annihilation, storage sites for defects (Beyerlein et al,2015;Demkowicz et al,2008). For example, the interaction of interface with radiation induced point defect, e.g. a vacancy can be described by one-dimensional linear partial differential equation that governs the evolution of vacancy concentration. Opportunities exist to couple multiple interface defect interactions to develop complex physics mechanism based models.

Strengthening models of metallic nanocomposite can also depends on the interface stability model. For example, in $\mathrm{Cu}-\mathrm{Nb}$ composite, the $\mathrm{Nb}$ filaments tend to break up into segments under elevated temperature (Sandim et al,2004). This spheroidization phenomena decrease the interface area and weaken the interfaces' barrier effect to lattice dislocations motion. The stability and evolution of interfaces has been studied in details for two metal phase composites under elevated temperature (Tian et al,2014) and under radiation (Zhang et al,2013). Tian et al (Tian et al,2014) first used phase field approach to study the interfacial morphological change at elevated temperature. Their 
results suggested that the stability of interface obey Rayleigh's instability criteria that is originally derived from the jets of fluid, i.e. the interface will be stable when the periodic interface perturbation wavelength is less than the initial rod circumference and will be unstable against these interface perturbations and evolve into segments when the perturbation wavelength is larger than initial rod circumference. Zhang et al (Zhang et al,2013) studied the stability of $\mathrm{Cu}-\mathrm{Nb}$ interface under radiation and found that the interface is morphologically stable when individual layer thicknesses is between 2 to $4 \mathrm{~nm}$. They used molecular dynamics to generate the initial concentration mapping for phase field simulation. Their results suggested that most interface survived and were stable during radiation except one $\mathrm{Nb}$ layer pinched off.

\section{Latest developments of novel nanostructured materials}

\section{Novel nanostructured materials with synergy of high strength and high ductility}

Most nanostructured materials have limited ductility (less than 3\%) due to the inhomogeneous plastic deformation (Wang et al,2002), which hindered their practical applications. Recently, many novel nanostructured materials have emerged to achieve the synergy of high strength and high ductility (Wang et al,2002;Ma et al,2017;Witkin et al,2003;Ma,2006; Kou et al,2014;Zhao et al,2010). For example, Wang et al (Wang et al,2002) first designed a nanostructured $\mathrm{Cu}$ material by thermomechanical treatment that possess a bimodal grain size distribution (i.e. the nanoscale grains embedded by microscale grains. The high strength primarily came from the nanoscale matrix grains, while high ductility was a result of the inhomogeneous bimodal grain size distribution microstructure that stabilize the tensile deformation. Similar concept of designing multiphase nanoscale microstructure by using microscale ductile crystalline phases to toughen nanostructured matrix was also reported by $\mathrm{He}$ at al (He et al,2002). Zhao et al (Zhao et $a l, 2008)$ reported a bulk nanostructured Nickel with high ductility and strength. They attributed the high ductility to substantially reduced processing artifacts, the existence of high-angle grain boundaries and multimodal grain size distributions. Furthermore, the largescale production of bulk nanostructured materials needs to address the challenge of maintaining a decent formability for nanostructured materials. Therefore, Liddicoat et al (Liddicoat et al,2010) engineered a super high strength nanostructured aluminum alloy with complex microstructural hierarchy to improve its ductility for large scale production.

Various methods have been proposed for the overcome of this strength-ductility tradeoff (Ma,2006;Zhao et al,2010). One approach would be the previously discussed mixture of the length scales by creating a multimodal grain size distribution. This can be done by traditional thermomechanical treatment to achieve recrystallization in the bulk samples or by the consolidation of a mixture of powders with different grain sizes. Another approach is a similar concept by embedding microscale ductile phase in a strong nanocrystalline matrix phase to form composite as done by $\mathrm{He}$ et al (He et al,2002). The complementary properties are attributed to the mixture of two or multiple phases with different length scales and properties. Other structural design approaches include nano-precipitates/nanoparticles dispersion,nanotwins, lowering dynamic recovery by using cryogenic temperatures (Wang et al,2004). All these approaches share a common design principle of creating heterogeneous structures to enhance uniform tensile ductility (Ma et al,2017).

\section{Novel nanostructured materials with synergy of high strength and high conductivity}

The high strength nanostructured materials usually require functional properties to be applied in multifunctional applications, such as power transmission cables (Tian et al,2013). However, conventional strengthening mechanisms often lead to reduced conductivity. This strength-conductivity tradeoff needs to be seriously considered when designing novel nanostructured materials. Various approaches have been proposed to address this strengthconductivity trade-off. The following examples are highlighted routes to balance the strength and conductivity of novel nanostructured materials.

\section{Nanoprecipitate reinforced composite}

The first approach is to introduce nanoscale precipitate particles into nanostructured matrix (Li et al,2016). Li et al (Li et al,2016) introduced $\mathrm{Cu}_{5} \mathrm{Zr}$ precipitated particles into $\mathrm{Cu}$ matrix composed of deformation twins to achieve a good combination of strength and electrical conductivity. Their electrical conductivity only slightly decreased due to refine grains leading to enhanced grain scattering (Tian et al,2014). Similar concept was adopted by Islamgaliev et al (Islamgaliev et al,2014) to use small $\mathrm{Cr}$ precipitate particles to achieve the high strength and high electrical conductivity of nanostructured $\mathrm{Cu}-\mathrm{Cr}$ alloy. The high strength and high electrical conductivity has also been achieved by embedding spheroidal coherent $\mathrm{Al}_{3}(\mathrm{Zr}, \mathrm{Sc}$ Er) precipitates in the Al matrix (Vo et al,2014;BoothMorrison et al,2011; Knipling et al,2008) or embedding $\mathrm{Mg}, \mathrm{Si}$ rich precipitates inside dilute Al alloy matrix (Sauvage et al,2015; Flores et al,2018). These nanoprecipitates caused only a slight electron scattering due to their strong coherency with matrix metal. These nano-precipitate strengthened nanostructured materials usually possess complex nanoscale features, such as grain size distribution, a variety of precipitates with different size, density or distribution.

\section{Nanoscale metal filaments reinforced composite}

The second approach is to introduce ductile nanoscale second metal phase into nanostructured materials (Tian et al,2017). The incorporation of nanoscale pure metal as second phase into another metal matrix have been achieved in $\mathrm{Cu}-\mathrm{Nb}$ composite (Bevk et al,1978; 
Raabe et al,2010; Verhoeven et al,1986;Verhoeven et al,1990), Al-Ca composite (Tian et al,2017;Tian et al,2013), Al-Mg composite (Xu et al,1999), Al-Ti composite (Russell et al,1999) by either melting solidification process or powder metallurgy process. The key to achieve high strength and high conductivity in these metal-metal nanostructured materials is to find the optimal size of nanoscale second phase, so that strength can be enhanced through an approximate Hall-Petch relation while the conductivity only decreases slightly due to the fact that this optimal size of second phase is still much larger than the electron mean free path, rendering negligible amount of interface scattering (Tian et al,2014;Tian et al,2014).

Previous two approaches only minimize the decrease of electrical conductivity of high conductivity matrix materials. The third approach is to introduce super high conductivity carbon based nanomaterials (e.g. nanoparticles or nanotubes) into matrix materials to increase the electrical conductivity above that of matrix materials. These nanostructured materials can be either carbon nanotube reinforced composites or carbon nanoparticle reinforced composite (i.e. covetics). However, the full transfer of the excellent properties of carbon nanomaterials into matrix materials has been a major hinder to develop such nanostructured composites. The major challenges of using carbon based nanomaterials to improve the conductivity of matrix materials are to achieve the good dispersion of carbon nanomaterials in matrix materials and maintain good interfacial bonding (Neubauer et al,2010;Byengsoo et al,2006).

\section{Carbon nanotube reinforced composite}

Carbon nanotubes (CNTs) reinforced composites have been investigated extensively due to their excellent combination of properties and potential structural/multifunctional applications in automotive, aerospace, energy and electronics (Bakshi et al,2010;Ma et al,2010;Spitalsky et al,2010;Thostenson et al,2001). Most past investigations focus on polymer matrix composite due to the ease of processing and improving properties of polymer matrix by CNTs, though their strength and electrical conductivity is still far away from industrial applications (Spitalsky et $a l, 2010)$. The correct route to achieve high strength and high conductivity is to form CNTs reinforced metal matrix composites, which have attracted numerous attentions (Thostenson et al,2001). This requires a good dispersion and interfacial bonding of intact CNTs within matrix. A common approach of achieving this goal is to electrolessly depositing metal onto CNTs. The encapsulation of CNTs inside matrix can also protect the direct contact of CNTs with metal matrix for potential chemical reaction and degradation at elevated temperature. This process usually requires a critical chemical oxidation pre-treatment of CNTs by acid to attach functional groups onto CNTs (i.e. functionalization) to improve their solubility and dispersion in solvent and purify CNTs by removing the amorphous carbon and metal impurities (Datsyuk et al,2008). The temperature, oxidation duration and acid concentration of acid treatment are critical parameters needed to be controlled to optimize the functionalization and subsequent electro-less deposition process (Rosca et al,2005). For example, excessive temperature, duration and acid concentration would damage the surface of CNTs and create defective sites or even broken CNTs segments that would decrease the conductivity of CNTs.

The CNTs reinforced composite can also achieve high strength and high ductility by the previously mentioned techniques to achieve uniform CNTs dispersion (So et al,2016;Wang et al,2016). The strengthening role of carbon nanotube inside metal matrix was considered to act as both load bearing filler and forest dislocations. Therefore, So et al (So et al,2016) proposed a new modified shear-lag model considering the "Taylor-dispersion" hardening effect of CNTs. Wang et al (Wang et al,2016) identified a new strengthening mechanism in CNT metal composite to be the series-connection effect, i.e. multiple nanoscale grains are connected by a single carbon nanotube. Shin et al (Shin et al,2015) proposed a new strengthening model based on quantitative analysis of reinforcement efficiency parameters that are determined by the interface features. Though some interesting work have been done to understand the distinctive strengthening behavior of metal carbon nanotube composite, extensive research efforts are needed to fully uncover the strengthening mechanisms of metal CNTs composite and develop new reliable strengthening models that are robust to a wide range of design variables.

\section{Nanocarbon reinforced composite (covetics)}

For the third approach, nanoscale carbon phase is another reinforcement material to improve the conductivity of metal matrix to form so called covetic materials (Mete Bakir,2017). Covetic materials are formed by infusing molten metal with carbon based powders under an applied electric current. This has been done in a range of metals such as $\mathrm{Cu}$ (Isaacs et al,2015;Knych et al,2014), Al (Brown et al,2014), Ag (Jaim et al,2017;Salamanca-Riba et al,2015). These materials have higher electrical and thermal conductivity than that of matrix metals, thus can be applied in various energy efficient related applications. Other properties such as transparency and resistance to oxidation could also exist. Their excellent conductivity properties should be attributed to the strong covalent-like interfacial bonding between the nanocarbon phases and their metal matrix, though the exact nature of this bonding is still unknown and being investigated by various researchers. The form of nanocarbon in covetics is still uncertain, though crystalline graphene nanoribbons and sheets with different length and conductivity have been observed along with some degree of amorphous carbon in $\mathrm{Al}$ and Ag covetics (Jaim et al,2017). The production of covetics by this conversion of inexpensive carbon powder to nanocarbon via conventional melting can be scalable to tonnage quantities and have significant economic benefits. 
The covetic materials provide a new route to achieve high strength (e.g. 30\% strength increase for $\mathrm{Al}$ ) and high electrical and thermal conductivity (e.g. 50\% thermal conductivity increase for $\mathrm{Cu}$ ) by using carbon nanostructures (Mete Bakir,2017). The primary challenges of studying covetics lies in the high sensitivity to variations of their processing conditions, the characterization of their carbon nanoscale structures, carbon content distribution and interfacial bonding, the wide variation of measured properties. Covetics are emerging materials and are undergoing active experimental research to understand their processing-nanostructure-property relation. Tremendous amount of opportunities exists to understand the distinctive relation between their complex nanostructure and strength by developing new strengthening models for covetics.

\section{Novel nanostructured materials by additive manufacturing}

Additive manufacturing is an advanced manufacturing technique that build complex shaped material layer by layer with great dimensional accuracy for rapid prototyping of new materials in contrast with conventional casting or other subtractive forming techniques (Sames et al,2016;Gu et al,2012;Campbell et al,2013;Anderson et al). Powder bed fusion (e.g. selective laser melting) and directed energy deposition are two most popular additive manufacturing techniques for fabricating metallic materials (Anderson et $a l$ ). Additive manufacturing is a very promising method to introduce nanomaterials into matrix to form multifunctional nanocomposites. This can be generally done by introducing nanomaterials intermittently during the 3D printing of the host matrix material or by preparing the feedstock as the powder mixture of host matrix and nanomaterials for subsequent 3D printing.

One of the challenges in $3 \mathrm{D}$ printing is to main the high quality of final finished parts. The high quality of feedstock powders is critical to achieve this goal. The quality of the powders (e.g. flowability, apparent density) is determined by various powder characteristics such as their size, shape, surface morphology (e.g. powder satellite content), surface chemical composition and amount of internal porosity. A spherical powder shape is beneficial to enhance flowability, and loose powder packing in all additive manufacturing techniques. Narrow particle size distributions are preferred in additive manufacturing techniques to maintain a constant feeding rate, such as 15-45 $\mu \mathrm{m}$ for powder bed fusion (Anderson et al). The satellites attaching to the powder surface can hinder the powder flowability and uniform packing. These characteristics requirements are in contrast with the requirements of powder compaction in conventional powder metallurgy, which prefers coarse powders with a wide particle size distribution and irregular shape to obtain high density green compacts by minimizing the surface impurities and promoting the mechanical interlocking of particles (Wang et al,2008; Sevillano,2011; Farley et al,1968; Radchenko,2004;
Nikolakakis et al,1988). Due to improper storage and handling of powders, chemical impurities such as oxides and hydroxides (due to the absorption of water/moisture) can exist on powder surface to impede flowability, which needs either a better method for high quality powder production (Anderson et $a l, 2001$ ) or a post-processing degassing treatment in vacuum to remove the trapped moistures and gases (Flumerfelt,1998). For example, Al powders degassing was done at about $165{ }^{\circ} \mathrm{C}$ to achieve a maximum moisture liberation rate (Litvintsev et al,1967). The powder production processing can significantly affect the porosity trapped inside powders (Anderson et $a l, 2002)$. Coarse powders are more prone to trap gas and form pores than fine powders (Anderson et al,2018). The porosity can reduce mechanical properties and limit the final parts' service life, and therefore should be eliminated as much as possible during the initial feedstock powder production.

Although all these powder quality requirements (such as narrow particle size distribution and spherical powder shape) place a high demand on the production capacity of industrial vendors that make the powder feedstocks of additive manufacturing expensive, additive manufacturing provides an extra route to design and rapid prototype high strength, high ductility multifunctional composites. Liu et al (Liu et al,2017) used selective laser melting to produce stainless steel with high strength and high ductility by introducing dislocation network. This dislocation network structure is stable during plastic deformation and can have two effects on the deformation behavior by slowing down the dislocation motion and by promoting the formation of nano-twins. However, high strength of additive manufactured parts may be difficult to achieve. This decrease of mechanical properties has been observed in selective laser melting fabricated Al matrix SiC reinforced composite due to the grain coarsening and porosity during the melting and solidification (Gu et al,2015).

Room temperature additive manufacturing techniques to create metal matrix composite would be a very promising way to resolve this issue. Ultrasonic additive manufacturing is such a novel technique that use high frequency ultrasonically vibration force to disrupt surface contaminants to create clean surfaces for welding two dissimilar materials by solid state bonding (Ram et al,2007;Hahnlen et al,2014). The benefits of this technique are the low dimensional error and the elimination of residual stresses in the finished parts that would otherwise exist in parts produced by the melting and solidification, which enable additive manufacturing to be applied in any melting-prohibitive applications. It has been successfully used to produce $\mathrm{Al}$ alloy matrix composite with a number of reinforcement such as SiC, Inconel, brass and stainless steel (Ram et al,2007;Manfredi et al,2014). 
Recently, Vyatskikh et al developed a lithography based process to increase the resolution from 20-50 um to $100 \mathrm{~nm}$, which enable them to create complex 3D nano-architected metals in sub-micron resolution (Vyatskikh et al,2018). Other innovation of 3D printing in creating nanostructures is by using hierarchical inks to create fiber-reinforced composite architectures such as wood-like cellular composites (Compton et al,2014). All these research studies highlight the possibility of tailoring the microstructure of advanced metallic materials through additive manufacturing. Substantial efforts are needed to understand additive manufacturing processing-microstructure-properties relation for developing strengthening models and designing novel nanostructured metallic materials with exceptional properties.

In summary, these nanostructured materials are usually comprised of complex microstructural hierarchy that interacts at nanoscale to make the quantitative description of microstructure mechanical properties relation challenging. For example, a simultaneous observation of nanoscale grains, high density of dislocations, nanoscale intergranular solute structures, intra-granular solute clusters have been conducted (Liddicoat et al,2010). Conventional strengthening mechanisms, e.g. solid solution strengthening, precipitate strengthening, second phase dispersion strengthening, grain boundaries strengthening, interfacial strengthening, inevitably lead to reduced ductility (Wen et al,2013). These nanostructured materials usually required addition strengthening mechanisms, such as the dislocation source limited hardening that needs a higher stress to activate additional dislocation sources (Kamikawa et al,2009). Furthermore, the complex nanoscale microstructure in these bulk nanostructured materials are often difficult to reproduce due to the involvement of many processing parameters. The resultant microstructural variations (e.g. variation of the grain size distribution and grain shape) is responsible for the fluctuation of material properties, which make it difficult to predict their properties by mathematical modeling. Therefore, opportunities exist to develop new strengthening models for these novel nanostructured materials to enable the design of more advanced nanostructured materials that expands the current microstructure-property design space.

\section{Conclusions}

This paper reviewed the current progress of developing strengthening models for nanostructured materials, with focus on nanocrystalline materials and nanocomposite materials. Multiple approaches such as the rule of mixtures, the physics based mechanism, the combined approach, the strain gradient theory are discussed in detail to develop strengthening models. Latest developments of novel nanostructured materials are highlighted to address the strength-ductility and strength-conductivity trade-offs for their practical structural and multifunctional applications. Their complex hierarchy of multi-phase nanoscale microstructure advocates potential challenges and tremendous amount of opportunities in using these existing approaches or devising novel approaches to develop new strengthening models for guiding the design of future advanced nanostructured materials with unprecedented properties.

\section{Acknowledgements}

LL would like to acknowledge the support from the National Science Foundation under grant number CMMI 17-0267.

\section{References}

Gleiter, H. (2000), Nanostructured materials: basic concepts and microstructure,Acta Materialia, 48(1), pp 1-29.

Gleiter, H. (1989), Nanocrystalline materials,Progress in Materials Science, 33(4), pp 223-315.

Meyers, M. A., Mishra, A. and Benson, D. J. (2006), Mechanical properties of nanocrystalline materials,Progress in Materials Science, 51(4), pp 427-556.

Suryanarayana, C. (1994), Structure and properties of nanocrystalline materials,Bulletin of Materials Science, 17(4), pp 307-346.

Beyerlein, I. J., Demkowicz, M. J., Misra, A. and Uberuaga, B. P. (2015), Defect-interface interactions,Progress in Materials Science, 74, pp 125-210.

Raabe, D., Herbig, M., Sandlöbes, S., Li, Y., Tytko, D., Kuzmina, M., Ponge, D. and Choi, P. P. (2014), Grain boundary segregation engineering in metallic alloys: A pathway to the design of interfaces,Current Opinion in Solid State and Materials Science, 18(4), pp 253-261.

Ma, A., Roters, F. and Raabe, D. (2006), On the consideration of interactions between dislocations and grain boundaries in crystal plasticity finite element modeling - Theory, experiments, and simulations,Acta Materialia, 54(8), pp 2181-2194.

Chen, M., Ma, E., Hemker, K. J., Sheng, H., Wang, Y. and Cheng, $X$. (2003), Deformation Twinning in Nanocrystalline Aluminum,Science, 300(5623), pp 1275-1277.

Dao, M., Lu, L., Asaro, R. J., De Hosson, J. T. M. and Ma, E. (2007), Toward a quantitative understanding of mechanical behavior of nanocrystalline metals,Acta Materialia, 55(12), pp 4041-4065.

Tian, L., Anderson, I., Riedemann, T., Russell, A. and Kim, H. (2013), Prospects for novel deformation processed Al/Ca composite conductors for overhead high voltage direct current (HVDC) power transmission,Electric Power Systems Research, 105, pp 105-114.

Tian, L., Russell, A., Riedemann, T., Mueller, S. and Anderson, I. (2017), A deformation-processed Al-matrix/Cananofilamentary composite with low density, high strength, and high conductivity,Materials Science and Engineering: A, 690, pp 348-354.

Suryanarayana, C., Mukhopadhyay, D., Patankar, S. N. and Froes, F. H. (2011), Grain size effects in nanocrystalline materials,Journal of Materials Research, 7(8), pp 2114 2118

Rostislav, A. A. and Aleksandr, M. G. (2009), Strength of nanostructures,Physics-Uspekhi, 52(4), pp 315.

Bringa, E. M., Caro, A., Wang, Y., Victoria, M., McNaney, J. M., Remington, B. A., Smith, R. F., Torralva, B. R. and Van 
Swygenhoven, H. (2005), Ultrahigh Strength in Nanocrystalline Materials Under Shock Loading,Science, 309(5742), pp 1838-1841.

Schiøtz, J. and Jacobsen, K. W. (2003), A Maximum in the Strength of Nanocrystalline Copper,Science, 301(5638), pp 1357-1359.

Mercier, S., Molinari, A. and Estrin, Y. (2007), Grain size dependence of strength of nanocrystalline materials as exemplified by copper: an elastic-viscoplastic modelling approach,Journal of Materials Science, 42(5), pp 14551465.

Carlton, C. E. and Ferreira, P. J. (2007), What is behind the inverse Hall-Petch effect in nanocrystalline materials?,Acta Materialia, 55(11), pp 3749-3756.

Hahn, H. and Padmanabhan, K. A. (1997), A model for the deformation of nanocrystalline materials,Philosophical Magazine B, 76(4), pp 559-571.

Yamakov, V., Wolf, D., Phillpot, S. R., Mukherjee, A. K. and Gleiter, H. (2003), Deformation-mechanism map for nanocrystalline metals by molecular-dynamics simulation,Nature Materials, 3, pp 43.

Voyiadjis, G. Z. and Deliktas, B. (2010), Modeling of strengthening and softening in inelastic nanocrystalline materials with reference to the triple junction and grain boundaries using strain gradient plasticity,Acta Mechanica, 213(1), pp 3-26.

Gutkin, M. Y., Ovid'ko, I. A. and Pande, C. S. (2004), Yield stress of nanocrystalline materials: role of grain-boundary dislocations, triple junctions and Coble creep,Philosophical Magazine, 84(9), pp 847-863.

Kocks, U. F. (1970), The relation between polycrystal deformation and single-crystal deformation,Metallurgical and Materials Transactions B, 1(5), pp 1121-1143.

Gryaznov, V. G., Gutkin, M. Y., Romanov, A. E. and Trusov, L. I. (1993), On the yield stress of nanocrystals,Journal of Materials Science, 28(16), pp 4359-4365.

Carsley, J. E., Ning, J., Milligan, W. W., Hackney, S. A. and Aifantis, E. C. (1995), A simple, mixtures-based model for the grain size dependence of strength in nanophase metals, Nanostructured Materials, 5(4), pp 441-448.

Gutkin, M. Y. and Ovid'ko, I. A. (1993), Disclinations and yield stress of metallic glass-nanocrystal composites,Nanostructured Materials, 2(6), pp 631-636

Kim, H. S. (1998), A composite model for mechanical properties of nanocrystalline materials,Scripta Materialia, 39(8), pp 1057-1061.

Konstantinidis, D. A. and Aifantis, E. C. (1998), On the "Anomalous" hardness of nanocrystalline materials,Nanostructured Materials, 10(7), pp 1111-1118.

Wang, N., Wang, Z., Aust, K. T. and Erb, U. (1995), Effect of grain size on mechanical properties of nanocrystalline materials,Acta Metallurgica et Materialia, 43(2), pp 519528

Tian, L. (2017), A Short Review on Mechanical Behavior of Nanocrystalline Materials,Int J Metall Met Phys, 2(1), pp 113

Grabski, M. W. and Korski, R. (1970), Grain boundaries as sinks for dislocations, The Philosophical Magazine: A Journal of Theoretical Experimental and Applied Physics, 22(178), pp 707-715.

Li, L., Anderson, P. M., Lee, M.-G., Bitzek, E., Derlet, P. and Swygenhoven, H. V. (2009), The stress-strain response of nanocrystalline metals: A quantized crystal plasticity approach,Acta Materialia, 57(3), pp 812-822.

Hahn, H., Mondal, P. and Padmanabhan, K. A. (1997), Plastic deformation of nanocrystalline materials, Nanostructured Materials, 9(1), pp 603-606.

Masumura, R. A., Hazzledine, P. M. and Pande, C. S. (1998), Yield stress of fine grained materials,Acta Materialia, 46(13), pp 4527-4534.
Pu, C., Gao, Y., Wang, Y. and Sham, T. L. (2017), Diffusioncoupled cohesive interface simulations of stress corrosion intergranular cracking in polycrystalline materials,Acta Materialia, 136(Supplement C), pp 21-31.

Jiaze, H. and Fuh-Gwo, Y. (2016), A quantitative damage imaging technique based on enhanced CCRTM for composite plates using 2D scan,Smart Materials and Structures, 25(10), pp 105022.

Kim, H. S., Estrin, Y. and Bush, M. B. (2000), Plastic deformation behaviour of fine-grained materials,Acta Materialia, 48(2), pp 493-504.

Zhu, R.-t., Zhou, J.-q., Ma, L. and Zhang, Z.-z. (2008), Mechanical model for yield strength of nanocrystalline materials under high strain rate loading,Journal of Central South University of Technology, 15(1), pp 447-452.

Zhu, B., Asaro, R. J., Krysl, P., Zhang, K. and Weertman, J. R. (2006), Effects of grain size distribution on the mechanical response of nanocrystalline metals: Part II,Acta Materialia, 54(12), pp 3307-3320.

Rupert, T. J., Trenkle, J. C. and Schuh, C. A. (2011), Enhanced solid solution effects on the strength of nanocrystalline alloys,Acta Materialia, 59(4), pp 1619-1631.

Bevk, J., Harbison, J. P. and Bell, J. L. (1978), Anomalous Increase in Strength of Insitu Formed $\mathrm{Cu}-\mathrm{Nb}$ Multifilamentary Composites,Journal of Applied Physics, 49(12), pp 6031-6038.

Trybus, C. L. and Spitzig, W. A. (1989), Characterization of the Strength and Microstructural Evolution of a Heavily ColdRolled Cu-20-Percent $\mathrm{Nb}$ Composite,Acta Metallurgica, 37(7), pp 1971-1981.

Tian, L., Kim, H., Anderson, I. and Russell, A. (2013), The microstructure-strength relationship in a deformation processed Al-Ca composite,Materials Science and Engineering: A, 570, pp 106-113.

Tian, L, (2015), Structure-property relationships in an Al matrix $\mathrm{Ca}$ nanofilamentary composite conductor with potential application in high-voltage power transmission, IOWA STATE UNIVERSITY PhD dissertation, pp 1-228.

Shaw, A., Tian, L. and Russell, A. M. (2016), Tensile Properties of High-purity Ca Metal,British Journal of Applied Science \& Technology, 15(6), pp 1-6.

Tian, L., Anderson, I., Riedemann, T. and Russell, A. (2017) Production of fine calcium powders by centrifugal atomization with rotating quench bath,Powder Technology, 308, pp 84-93.

Tian, L., Russell, A. and Anderson, I. (2014), A dislocationbased, strain-gradient-plasticity strengthening model for deformation processed metal-metal composites,Journal of Materials Science, 49(7), pp 2787-2794.

Tian, L., Anderson, I., Riedemann, T. and Russell, A. (2014), Modeling the electrical resistivity of deformation processed metal-metal composites,Acta Materialia, 77, pp 151-161.

Sinnott, S. B. and Dickey, E. C. (2003), Ceramic/metal interface structures and their relationship to atomic- and meso-scale properties,Materials Science and Engineering: R: Reports, 43(1), pp 1-59.

Funkenbusch, P. D., Lee, J. K. and Courtney, T. H. (1987), Ductile 2-Phase Alloys - Prediction of Strengthening at High Strains,Metallurgical Transactions a-Physical Metallurgy and Materials Science, 18(7), pp 1249-1256.

Brinckmann, S., Siegmund, T. and Huang, Y. (2006), A dislocation density based strain gradient model,International Journal of Plasticity, 22(9), pp 1784 1797.

Spitzig, W. A., Pelton, A. R. and Laabs, F. C. (1987), Characterization of the Strength and Microstructure of Heavily Cold-Worked Cu-Nb Composites,Acta Metallurgica, 35(10), pp 2427-2442. 
Trybus, C. L., Chumbley, L. S., Spitzig, W. A. and Verhoeven, J. D. (1989), Problems in Evaluating the Dislocation Densities in Heavily Deformed Cu-Nb Composites,Ultramicroscopy, 30(3), pp 315-320.

Raabe, D. and Hangen, U. (1995), Introduction of a Modified Linear Rule of Mixtures for the Modeling of the Yield Strength of Heavily Wire Drawn in-Situ Composites,Composites Science and Technology, 55(1), pp 57-61.

Huang, Y., Qu, S., Hwang, K. C., Li, M. and Gao, H. (2004), A conventional theory of mechanism-based strain gradient plasticity,International Journal of Plasticity, 20(4), pp 753782.

Fleck, N. A., Muller, G. M., Ashby, M. F. and Hutchinson, J. W. (1994), Strain gradient plasticity: Theory and experiment,Acta Metallurgica et Materialia, 42(2), pp 475487.

Stölken, J. S. and Evans, A. G. (1998), A microbend test method for measuring the plasticity length scale,Acta Materialia, 46(14), pp 5109-5115.

Shell De Guzman, M., Neubauer, G., Flinn, P. and Nix, W. D. (2011), The Role of Indentation Depth on the Measured Hardness of Materials, MRS Proceedings, 308, pp.

Lloyd, D. J. (1994), Particle reinforced aluminium and magnesium matrix composites,International Materials Reviews, 39(1), pp 1-23.

Abu Al-Rub, R. K. and Voyiadjis, G. Z. (2006), A physically based gradient plasticity theory,International Journal of Plasticity, 22(4), pp 654-684.

Gao, H., Huang, Y., Nix, W. D. and Hutchinson, J. W. (1999), Mechanism-based strain gradient plasticity- I. Theory,Journal of the Mechanics and Physics of Solids, 47(6), pp 1239-1263.

Ashby, M. F. (1970), The deformation of plastically nonhomogeneous materials, The Philosophical Magazine: A Journal of Theoretical Experimental and Applied Physics, 21(170), pp 399-424.

Demkowicz, M. J., Hoagland, R. G. and Hirth, J. P. (2008), Interface Structure and Radiation Damage Resistance in $\mathrm{Cu}-\mathrm{Nb}$ Multilayer Nanocomposites,Physical Review Letters, 100(13), pp 136102.

Sandim, H. R. Z., Sandim, M. J. R., Bernardi, H. H., Lins, J. F. C. and Raabe, D. (2004), Annealing effects on the microstructure and texture of a multifilamentary $\mathrm{Cu}-\mathrm{Nb}$ composite wire,Scripta Materialia, 51(11), pp 1099-1104.

Tian, L. and Russell, A. (2014), Phase field study of interfacial diffusion-driven spheroidization in a composite comprised of two mutually insoluble phases,The Journal of Chemical Physics, 140(12), pp 124706.

Zhang, L. and Demkowicz, M. J. (2013), Morphological stability of $\mathrm{Cu}-\mathrm{Nb}$ nanocomposites under high-energy collision cascades,Applied Physics Letters, 103(6), pp.

Wang, Y., Chen, M., Zhou, F. and Ma, E. (2002), High tensile ductility in a nanostructured metal,Nature, 419, pp 912.

Ma, E. and Zhu, T. (2017), Towards strength-ductility synergy through the design of heterogeneous nanostructures in metals,Materials Today, 20(6), pp 323331.

Witkin, D., Lee, Z., Rodriguez, R., Nutt, S. and Lavernia, E. (2003), Al-Mg alloy engineered with bimodal grain size for high strength and increased ductility,Scripta Materialia, 49(4), pp 297-302.

Ma, E. (2006), Eight routes to improve the tensile ductility of bulk nanostructured metals and alloys,JOM, 58(4), pp 4953.

Kou, H., Lu, J. and Li, Y. (2014), High-Strength and HighDuctility Nanostructured and Amorphous Metallic Materials,Advanced Materials, 26(31), pp 5518-5524.

Zhao, Y., Zhu, Y. and Lavernia, E. J. (2010), Strategies for Improving Tensile Ductility of Bulk Nanostructured
Materials,Advanced Engineering Materials, 12(8), pp 769778.

He, G., Eckert, J., Löser, W. and Schultz, L. (2002), Novel Tibase nanostructure-dendrite composite with enhanced plasticity,Nature Materials, 2, pp 33.

Zhao, Y., Topping, T., Bingert, J. F., Thornton, J. J., Dangelewicz, A. M., Li, Y., Liu, W., Zhu, Y., Zhou, Y. and Lavernia, E. J. (2008), High Tensile Ductility and Strength in Bulk Nanostructured Nickel,Advanced Materials, 20(16), pp 3028-3033.

Liddicoat, P. V., Liao, X.-Z., Zhao, Y., Zhu, Y., Murashkin, M. Y., Lavernia, E. J., Valiev, R. Z. and Ringer, S. P. (2010), Nanostructural hierarchy increases the strength of aluminium alloys, Nature Communications, 1, pp 63.

Wang, Y. M., Ma, E., Valiev, R. Z. and Zhu, Y. T. (2004), Tough Nanostructured Metals at Cryogenic Temperatures,Advanced Materials, 16(4), pp 328-331.

Li, R., Kang, H., Chen, Z., Fan, G., Zou, C., Wang, W., Zhang, S., Lu, Y., Jie, J., Cao, Z., Li, T. and Wang, T. (2016), A promising structure for fabricating high strength and high electrical conductivity copper alloys,Scientific Reports, 6, pp 20799.

Islamgaliev, R. K., Nesterov, K. M., Bourgon, J., Champion, Y. and Valiev, R. Z. (2014), Nanostructured $\mathrm{Cu}-\mathrm{Cr}$ alloy with high strength and electrical conductivity,Journal of Applied Physics, 115(19), pp 194301.

Vo, N. Q., Dunand, D. C. and Seidman, D. N. (2014), Improving aging and creep resistance in a dilute Al-Sc alloy by microalloying with $\mathrm{Si}, \mathrm{Zr}$ and Er,Acta Materialia, 63, pp 7385.

Booth-Morrison, C., Dunand, D. C. and Seidman, D. N. (2011), Coarsening resistance at $400^{\circ} \mathrm{C}$ of precipitationstrengthened Al-Zr-Sc-Er alloys,Acta Materialia, 59(18), pp 7029-7042.

Knipling, K. E., Dunand, D. C. and Seidman, D. N. (2008), Precipitation evolution in $\mathrm{Al}-\mathrm{Zr}$ and $\mathrm{Al}-\mathrm{Zr}-\mathrm{Ti}$ alloys during aging at $450-600^{\circ} \mathrm{C}$, Acta Materialia, 56(6), pp 1182-1195.

Sauvage, X., Bobruk, E. V., Murashkin, M. Y., Nasedkina, Y., Enikeev, N. A. and Valiev, R. Z. (2015), Optimization of electrical conductivity and strength combination by structure design at the nanoscale in $\mathrm{Al}-\mathrm{Mg}-\mathrm{Si}$ alloys, Acta Materialia, 98, pp 355-366.

Raabe, D., Choi, P.-P., Li, Y., Kostka, A., Sauvage, X., Lecouturier, F., Hono, K., Kirchheim, R., Pippan, R. and Embury, D. (2010), Metallic composites processed via extreme deformation: Toward the limits of strength in bulk materials,MRS Bulletin, 35(12), pp 982-991.

Verhoeven, J. D., Schmidt, F. A., Gibson, E. D. and Spitzig, W. A. (1986), Copper-Refractory Metal-Alloys,Journal of Metals, 38(9), pp 20-24.

Verhoeven, J. D., Spitzig, W. A., Jones, L. L., Downing, H. L., Trybus, C. L., Gibson, E. D., Chumbley, L. S., Fritzemeier, L. G. and Schnittgrund, G. D. (1990), Development of Deformation Processed Copper Refractory-Metal Composite Alloys,Journal of Materials Engineering, 12(2), pp 127-139.

Xu, K., Russell, A. M., Chumbley, L. S., Laabs, F. C., Gantovnik, V. B. and Tian, Y. (1999), Characterization of strength and microstructure in deformation processed $\mathrm{Al}-\mathrm{Mg}$ composites,Journal of Materials Science, 34(24), pp 59555959.

Russell, A. M., Lund, T., Chumbley, L. S., Laabs, F. A., Keehner, L. L. and Harringa, J. L. (1999), A high-strength, highconductivity Al-Ti deformation processed metal metal matrix composite,Composites Part a-Applied Science and Manufacturing, 30(3), pp 239-247.

Neubauer, E., Kitzmantel, M., Hulman, M. and Angerer, P. (2010), Potential and challenges of metal-matrixcomposites reinforced with carbon nanofibers and carbon nanotubes,Composites Science and Technology, 70(16), pp 2228-2236. 
Byengsoo, L., Chul-ju, K, Bumjoon, K, Untae, S., Seyoung, 0. Byung-ho, S., Jee-hoon, C. and Seunghyun, B. (2006), The effects of interfacial bonding on mechanical properties of single-walled carbon nanotube reinforced copper matrix nanocomposites,Nanotechnology, 17(23), pp 5759.

Bakshi, S. R., Lahiri, D. and Agarwal, A. (2010), Carbon nanotube reinforced metal matrix composites - a review,International Materials Reviews, 55(1), pp 41-64.

Ma, P.-C., Siddiqui, N. A., Marom, G. and Kim, J.-K. (2010), Dispersion and functionalization of carbon nanotubes for polymer-based nanocomposites: A review,Composites Part A: Applied Science and Manufacturing, 41(10), pp 13451367.

Spitalsky, Z., Tasis, D., Papagelis, K. and Galiotis, C. (2010), Carbon nanotube-polymer composites: Chemistry, processing, mechanical and electrical properties,Progress in Polymer Science, 35(3), pp 357-401.

Thostenson, E. T., Ren, Z. and Chou, T.-W. (2001), Advances in the science and technology of carbon nanotubes and their composites: a review,Composites Science and Technology, 61(13), pp 1899-1912.

Datsyuk, V., Kalyva, M., Papagelis, K., Parthenios, J., Tasis, D., Siokou, A., Kallitsis, I. and Galiotis, C. (2008), Chemical oxidation of multiwalled carbon nanotubes,Carbon, 46(6) pp 833-840.

Rosca, I. D., Watari, F., Uo, M. and Akaska, T. (2005), Oxidation of multiwalled carbon nanotubes by nitric acid,Carbon, 43(15), pp 3124-3131.

So, K. P., Liu, X., Mori, H., Kushima, A., Park, J. G., Kim, H. S., Ogata, S., Lee, Y. H. and Li, J. (2016), Ton-scale metalcarbon nanotube composite: The mechanism of strengthening while retaining tensile ductility,Extreme Mechanics Letters, 8, pp 245-250.

Wang, H., Zhang, Z.-H., Hu, Z.-Y., Wang, F.-C., Li, S.-L., Korznikov, E., Zhao, X.-C., Liu, Y., Liu, Z.-F. and Kang, Z (2016), Synergistic strengthening effect of nanocrystalline copper reinforced with carbon nanotubes,Scientific Reports, 6, pp 26258.

Shin, S. E., Choi, H. J., Hwang, J. Y. and Bae, D. H. (2015), Strengthening behavior of carbon/metal nanocomposites,Scientific Reports, 5, pp 16114.

Mete Bakir, I. J. (2017), Novel metal-carbon nanomaterials: A review on covetics,Advanced Materials Letters, 8(9), pp 884-890.

Isaacs, R. A., Zhu, H., Preston, C., Mansour, A., LeMieux, M., Zavalij, P. Y., Jaim, H. M. I., Rabin, O., Hu, L. and SalamancaRiba, L. G. (2015), Nanocarbon-copper thin film as transparent electrode,Applied Physics Letters, 106(19), pp 193108.

Knych, T., Kwaśniewski, P., Kiesiewicz, G., Mamala, A. Kawecki, A. and Smyrak, B. (2014), Characterization of Nanocarbon Copper Composites Manufactured in Metallurgical Synthesis Process,Metallurgical and Materials Transactions B, 45(4), pp 1196-1203.

Brown, L., Joyce, P., Forrest, D. and Salamanca-Riba, L. (2014), Physical and Mechanical Characterization of a Nanocarbon Infused Aluminum-Matrix Composite, pp.

Jaim, H. M. I., Cole, D. P. and Salamanca-Riba, L. G. (2017), Characterization of carbon nanostructures in $\mathrm{Al}$ and $\mathrm{Ag}$ covetic alloys,Carbon, 111, pp 309-321.

Salamanca-Riba, L. G., Isaacs, R. A., LeMieux, M. C., Wan, J., Gaskell, K., Jiang, Y., Wuttig, M., Mansour, A. N., Rashkeev, S. N., Kuklja, M. M., Zavalij, P. Y., Santiago, J. R. and Hu, L. (2015), Synthetic Crystals of Silver with Carbon: 3D Epitaxy of Carbon Nanostructures in the Silver Lattice,Advanced Functional Materials, 25(30), pp 47684777.

Sames, W. J., List, F. A., Pannala, S., Dehoff, R. R. and Babu, S. S. (2016), The metallurgy and processing science of metal additive manufacturing,International Materials Reviews, 61(5), pp 315-360.

Gu, D. D., Meiners, W., Wissenbach, K. and Poprawe, R. (2012), Laser additive manufacturing of metallic components: materials, processes and mechanisms,International Materials Reviews, 57(3), pp 133-164.
Campbell, T. A. and Ivanova, O. S. (2013), 3D printing of multifunctional nanocomposites,Nano Today, 8(2), pp 119-120.

Anderson, I. E., White, E. M. H. and Dehoff, R. (2018) Feedstock powder processing research needs for additive manufacturing development,Current Opinion in Solid State and Materials Science, $\mathrm{pp}$.

Wang, J.-z., Qu, X.-h., Yin, H.-q., Yi, M.-j. and Yuan, X.-j. (2008), Effect of particle size distribution on green properties during high velocity compaction,Frontiers of Materials Science in China, 2(4), pp 392.

Sevillano, J. G. (2011), Size effects in powder compaction,Journal of Materials Research, 16(5), pp 12381240 .

Farley, R. and Valentin, F. H. H. (1968), Effect of particle size upon the strength of powders,Powder Technology, 1(6), pp 344-354.

Radchenko, A. K. (2004), Mechanical properties of unsintered pressing. I. Phenomenological relations for unsintered pressing strength,Powder Metallurgy and Metal Ceramics, 43(9), pp 447-460.

Nikolakakis, I. and Pilpel, N. (1988), Effects of particle shape and size on the tensile strengths of powders,Powder Technology, 56(2), pp 95-103.

Anderson, I. E. and Foley, J. C. (2001), Determining the role of surfaces and interfaces in the powder metallurgy processing of aluminum alloy powders,Surface and Interface Analysis, 31(7), pp 599-608.

Flumerfelt, J, (1998), Aluminum powder metallurgy processing, Iowa State University PhD dissertation, pp. 1154.

Litvintsev, A. I. and Arbuzova, L. A. (1967), Kinetics of degassing of aluminum powders,Soviet Powder Metallurgy and Metal Ceramics, 6(1), pp 1-10.

Anderson, I. E. and Terpstra, R. L. (2002), Progress toward gas atomization processing with increased uniformity and control,Materials Science and Engineering: A, 326(1), pp 101-109.

Liu, L., Ding, Q., Zhong, Y., Zou, J., Wu, J., Chiu, Y.-L., Li, J., Zhang, Z., Yu, Q. and Shen, Z. (2017), Dislocation network in additive manufactured steel breaks strength-ductility trade-off,Materials Today, pp.

Gu, D., Chang, F. and Dai, D. (2015), Selective Laser Melting Additive Manufacturing of Novel Aluminum Based Composites With Multiple Reinforcing Phases,Journal of Manufacturing Science and Engineering, 137(2), pp 021010-021010-11.

Ram, G. D. J., Robinson, C., Yang, Y. and Stucker, B. E. (2007), Use of ultrasonic consolidation for fabrication of multimaterial structures,Rapid Prototyping Journal, 13(4), pp 226-235.

Hahnlen, R. and Dapino, M. J. (2014), NiTi-Al interface strength in ultrasonic additive manufacturing composites,Composites Part B: Engineering, 59, pp 101108.

Manfredi, D.,Calignano F., Krishnan M., Canali R., Ambrosio E.P., Biamino S., Ugues D., Pavese M., Fino P., (2014), Additive Manufacturing of Al Alloys and Aluminium Matrix Composites (AMCs), in: W.A. Monteiro (Ed.), Light Metal Alloys Applications Ch. 01, InTech, Rijeka, pp.

Vyatskikh, A., Delalande, S., Kudo, A., Zhang, X., Portela, C. M. and Greer, J. R. (2018), Additive manufacturing of 3D nanoarchitected metals, Nature Communications, 9(1), pp 593.

Compton, B. G. and Lewis, J. A. (2014), 3D-Printing of Lightweight Cellular Composites,Advanced Materials, 26(34), pp 5930-5935.

Wen, H., Topping, T. D., Isheim, D., Seidman, D. N. and Lavernia, E. J. (2013), Strengthening mechanisms in a highstrength bulk nanostructured $\mathrm{Cu}-\mathrm{Zn}-\mathrm{Al}$ alloy processed via cryomilling and spark plasma sintering,Acta Materialia, 61(8), pp 2769-2782.

Kamikawa, N., Huang, X., Tsuji, N. and Hansen, N. (2009), Strengthening mechanisms in nanostructured high-purity aluminium deformed to high strain and annealed,Acta Materialia, 57(14), pp 4198-4208. 